\title{
Identification and expression of amphioxus AmphiSmad1/5/8 and AmphiSmad4
}

\author{
YU XueSong ${ }^{1 \dagger}$, LI JianWei ${ }^{2 \dagger}$, LIU Hui $^{1}$, LI XiaoDan ${ }^{1}$, CHEN ShangWu ${ }^{1}$, \\ ZHANG HongWei ${ }^{2 *} \&$ XU AnLong ${ }^{1 *}$ \\ ${ }^{1}$ State Key Laboratory of Biocontrol, Open Laboratory for Marine Functional Genomics of State High-Tech Development Program, Guang- \\ dong Key Laboratory of Pharmaceutical Functional Genes, College of Life Sciences, \\ Sun Yat-Sen University, Guangzhou 510275, China; \\ ${ }^{2}$ Institute of Developmental Biology, College of Life Sciences, Shandong University, Jinan 250100, China
}

Received October 18, 2010; accepted November 6, 2010; published online January 25, 2011

\begin{abstract}
Smad family proteins are identified as intracellular signal mediators of the TGF- $\beta$ superfamily. In this study, we identified two novel members of the Smad family, termed as AmphiSmad1/5/8 and AmphiSmad4, from Chinese amphioxus. Both AmphiSmad1/5/8 and AmphiSmad4 showed a typical domain structure of Smad proteins consisting of conserved MH1 and MH2 domains. Phylogenetic analysis placed AmphiSmad1/5/8 in the Smad1, 5 and 8 subgroup of the R-Smad subfamily, and AmphiSmad4 in the Co-Smad subfamily. The spatial and temporal gene expression patterns of AmphiSmad1/5/8 and AmphiSmad4 showed that they may be involved in the embryonic development of notochord, myotome and alimentary canal, and may help to establish the specification of dorsal-ventral axis of amphioxus. Moreover, AmphiSmad1/5/8 and AmphiSmad4 showed extensive distribution in all adult tissues examined, suggesting that these two genes may play important roles in the morphogenesis of a variety of tissues especially notochord and gonad.
\end{abstract}

amphioxus, Smad, AmphiSmad1/5/8, AmphiSmad4, expression patterns, organogenesis, dorsal-ventral patterning

Citation: Yu X S, Li J W, Liu H, et al. Identification and expression of amphioxus AmphiSmad1/5/8 and AmphiSmad4. Sci China Life Sci, 2011, 54: 220-226, doi: $10.1007 / \mathrm{s} 11427-011-4136-3$

Members of the transforming growth factor- $\beta$ (TGF- $\beta$ ) superfamily regulate organogenesis and pattern formation during early embryogenesis, and in the adult they are involved in processes such as tissue repair and modulation of the immune system [1,2]. A pivotal role in intracellular TGF- $\beta$ signaling is played by Smad proteins which directly transmit incoming signals from the cell surface receptors to the nucleus. Smad family proteins were first characterized in the fruit fly Drosophila melanogaster [3,4], and then their orthologous proteins were subsequently cloned, and at least eight different kinds of Smad proteins have been identified in

$\dagger$ Contributed equally to this work

*Corresponding author (email: zhw@sdu.edu.cn; 1ssxal@mail.sysu.edu.cn) mammals [1,2]. Based on structural and functional properties, Smad proteins are divided into three subfamilies: receptor-regulated Smad (R-Smad: Smad1, Smad2, Smad3, Smad5 and Smad8), common partner Smad (Co-Smad: Smad4), and inhibitory Smad (I-Smad: Smad6 and Smad7) [5]. Different members of the Smad family have different roles in signaling. R-Smad are the direct substrates of activated type I receptors by which they are phosphorylated at a conserved $\mathrm{SS}(\mathrm{V} / \mathrm{M}) \mathrm{S}$ motif at their extreme carboxy-terminal end. Among R-Smad, two subgroups have been defined: Smad1, Smad5, and Smad8 transduce signaling by members of the BMP family, while Smad2 and Smad3 are specific for activin and TGF- $\beta$ proteins. Smad 4 is a common mediator of both pathways, while Smad6 and Smad7 function as signal- 
ing inhibitors [6,7]. Smad proteins have two highly conserved domains, the N-terminal MH1 domain and the C-terminal $\mathrm{MH} 2$ domain, which are linked by a divergent linker region. The $\mathrm{MH} 1$ domain is well conserved between the R-Smad and the Co-Smad, whereas the MH2 domain is highly conserved among all kinds of Smad proteins.

TGF- $\beta$ signaling pathways have been demonstrated to provide positional information during early embryogenesis in nematodes, insects, and vertebrates. Smad proteins function as signal transducers of TGF- $\beta$ superfamily in organisms ranging from worms to humans $[5,7,8]$. While important roles of Smad proteins were indicated in early developmental stages, much is still to be learned about their roles in later developmental processes and in the adults [9-11].

The cephalochordate amphioxus is widely believed to be the closest living invertebrate relative to vertebrates and a useful animal model for developmental study [12]. However, nothing is known yet about Smad proteins in this evolutionarily important organism. Whether the Smad proteins of amphioxus have the same function as their homologs in vertebrates is also unknown. In this study, we identified two Smad cDNA clones from Chinese amphioxus. Additionally, we investigated their expression patterns in different embryonic stages and in various adult tissues using in situ hybridization and real-time PCR, respectively.

\section{Materials and methods}

\subsection{Specimen collection}

Adults of Chinese amphioxus (Branchiostoma belcheri tsingtauense) were collected near Shazikou, Qingdao, China, during the summer breeding season. Matured males and females were spawned in the laboratory. After fertilization, the synchronously developing embryos of various developmental stages were reared in filtered seawater at $25^{\circ} \mathrm{C}$, then collected and fixed.

\subsection{Identification of AmphiSmad1/5/8 and AmphiS- $\operatorname{mad4}$}

RT-PCR with total RNAs isolated from embryos of different developmental stages was performed with degenerated primers deduced from highly conserved amino acid sequences of Smad1 and Smad4 within the MH1 and MH2 domains. The primers used were 5'-CA(G/A)GG(A/T/C/G) GA(C/T)GA(A/G)GA(A/T/G)GA(G/A)AA(A/T/G)TGGGC3' (sense), 5'-G(A/G)TG(T/A/G)AT(TC)TC(A/G)ATCCA (A/G)CA(A/C/G)GG(T/C/G)GT-3' (antisense) for AmphiSmad1/5/8; 5'-AA(T/C)CC(A/T)TA(C/T)CACTA(C/T)GA $(\mathrm{A} / \mathrm{G})(\mathrm{A} / \mathrm{C}) \mathrm{G}(\mathrm{A} / \mathrm{G}) \mathrm{GT}-3^{\prime}$ ( sense), 5'-TC(A/T)ATCCA(A/G) CA(A/C)GG(T/C/G)GT(T/C)T(G/C)(T/C)TTGAT-3' (antisense) for AmphiSmad4. After an initial denaturation step of $4 \mathrm{~min}$ at $94^{\circ} \mathrm{C}$, the amplification consisted of 34 cycles of
$30 \mathrm{~s}$ at $94^{\circ} \mathrm{C}, 30 \mathrm{~s}$ at $52^{\circ} \mathrm{C}, 1 \mathrm{~min}$ at $72^{\circ} \mathrm{C}$, and then a final extension at $72^{\circ} \mathrm{C}$ for $10 \mathrm{~min}$. PCR products were subcloned into pGEM-T Easy Vector (Promega) and several randomly selected recombinant clones were chosen for sequencing. To obtain the complete sequences, 5'- and 3'-RACE were performed using the GeneRacer Kit (Invitrogen) according to the manufacturer's instructions. The gene-specific primers were designed based on the acquired cDNA fragments of AmphiSmad1/5/8 and AmphiSmad4. The primers used were as follows: 5' nested primer 5'-GCTTCTTGACGAGAGAGTCTACGGC-3', 5' primer 5'-TACTAACACTGGTGGCAGCACTGG-3', 3' primer 5'-GATTCCACCCCACCACTGTATG-3', and 3' nested primer 5'-GAGTTTTGTCAAGGCTGGGGAG-3' for AmphiSmad1/5/8; 5' nested primer 5'-TGGTTGGAGGTGTGCTGTATAGTCTG3', 5' primer 5'-GGGCGACTCTGTGTGTGGTTGGA-3'; 3' primer 5'-CAGAGTTACTACCTGGACCGTGAG-3', and 3' nested primer 5'-CGGACTACCCACGACAGAGCATC$3^{\prime}$ for AmphiSmad4. Touchdown PCR was performed to increase specificity and reduce background. PCR products of expected size were subcloned and sequenced as above.

\subsection{Sequence analyses and phylogenetic tree construc- tion}

The full length AmphiSmad1/5/8 and AmphiSmad4 cDNAs and their deduced amino acid sequences were analyzed by software Seqtools 8.0. All sequences generated were used to search for similarities using BLAST at web servers of the NCBI (http://www.ncbi.nlm.nih.gov). Additionally, a phylogenetic tree was constructed using the ClustalW 1.8 program and MEGA version 3.1. The neighbor-joining method was used to calculate the trees with 1000 bootstrap tests and gaps were handled with pairwise deletion.

\subsection{Whole-mount in situ hybridization}

Expression patterns of AmphiSmad1/5/8 and AmphiSmad4 were examined by whole-mount in situ hybridization on amphioxus embryos at differing developmental stages as described by Holland [13]. Primers were designed to amplify the poorly conserved linker region of AmphiSmad1/5/8 and AmphiSmad4 so as to increase specificity of the probes. The primers used for probe amplification were 5'-GGCTAAGGACACCAAGGAAG-3' (sense), 5'-GCGGTTATTCAGTTCGTAGTA-3' (antisense) for AmphiSmad1/5/8; 5'CGACCTTTCTGGGCTGACATT-3' (sense), 5'-CGAAGTAGGCAATAGAACACCA-3' (antisense) for AmphiSmad4. The 502 bp cDNA of AmphiSmad1/5/8 and 671 bp cDNA of AmphiSmad4 were amplified by designed primers. PCR products were subcloned into pGEM-T Easy Vector (Promega) and sequenced to confirm the inserted orientation. The templates were linearized and probes were synthesized by in vitro transcription using the DIG RNA Labeling Mix (Roche) following the manufacture's instructions. The 
hybridizations with the sense probes were used as controls. After in situ hybridization, the embryos were photographed as whole-mount. For histological examinations, some hybridized embryos were systematically cut into $6 \mu \mathrm{m}$ histological sections after being doubly embedded in agar-paraffin.

\subsection{Real-time PCR}

Total RNAs of different developmental stage embryos and different adult tissues were prepared using TRIzol reagent (Invitrogen) in accordance with the manufacture's instructions. This was followed by DNase I (RNase free, Takara) treatment and repurification in order to eliminate the genomic contamination. The cDNAs were synthesized with the Superscript III reverse transcriptase (Invitrogen) using the oligo d(T) primer. After cDNA template quantification, real-time PCR was performed with the ABI PRISIM 7900 sequence detection system. SYBR green real-time PCR mix (Toyobo) was used for the PCR reaction, with primer concentrations of $200 \mathrm{nmol} \mathrm{L}^{-1}$. The cytoplasmic $\beta$-actin gene of Chinese amphioxus was used as endogenous control to normalize the starting quantity of RNA. The primers used for such amplification were 5'-TGCCACATTTCCACAGTCGTTCC-3' (sense) and 5'-ATCTGTTCCTCGTTGTTCCTGTTC-3' (antisense) for AmphiSmad1/5/8; 5'-CTGTCTACACCACACTCAGTCTC-3' (sense) and 5'-ATGCTCGGACCTGTTCTGTTCAG-3' (antisense) for AmphiSmad4; 5'-ACAACCACCGCTGAGAGGGAAAT-3' (sense) and 5'CGAGGAAGGAAGGCTGGAAGAG-3' (antisense) for $a c$ tin. The size of the PCR products was $191 \mathrm{bp}$ for AmphiSmad1/5/8, 104 bp for AmphiSmad4 and 202 bp for actin. All samples were run in triplicate for $4 \mathrm{~min}$ at $95^{\circ} \mathrm{C}$, followed by 40 cycles of $30 \mathrm{~s}$ at $95^{\circ} \mathrm{C}, 30 \mathrm{~s}$ at $65^{\circ} \mathrm{C}, 1 \mathrm{~min}$ at $72^{\circ} \mathrm{C}$. Standard curves were constructed for target genes and $\beta$-actin with two-fold serial dilutions of cDNA. The threshold cycles and fold inductions were calculated by the ABI PRISIM 7900HD SDS software.

\section{Results}

\subsection{Sequence and phylogenetic analyses of AmphiS- mad1/5/8 and AmphiSmad4}

Both degenerate primer-based RT-PCR and RACE were performed, and two full length Smad cDNAs were identified from Chinese amphioxus. The cDNA of AmphiSmad1/5/8 (GenBank accession No. EF544709) is 2460 bp long, and its longest open reading frame encodes a protein of 464 amino acid residues. The cDNA of AmphiSmad4 (GenBank accession No. EF544710) is 1936 bp and encodes a protein of 591 amino acid residues. Both AmphiS$\operatorname{mad} 1 / 5 / 8$ and AmphiSmad4 showed a typical domain structure consisting of conserved $\mathrm{MH} 1$ and $\mathrm{MH} 2$ domains separated by a divergent proline-rich linker region. AmphiSmad1/5/8 has the conserved SS(V/M)S motif of the R-Smad subfamily at its extreme carboxy-terminal end, but AmphiSmad4 lacks the SS(V/M)S motif. The structure analysis showed that AmphiSmad1/5/8 belongs to the R-Smad subfamily and AmphiSmad4 belongs to the Co-Smad subfamily.

Phylogenetic analysis also placed AmphiSmad1/5/8 in the Smad1, 5 and 8 subgroup of R-Smad subfamily, and AmphiSmad4 in the Co-Smad subfamily (Figure 1). The phylogenetic tree showed that AmphiSmad1/5/8 and AmphiSmad4 might be the archetype of vertebrate related Smad proteins, and they probably originated from the duplication of a common ancestor gene after splitting from the plathyelminthes, arthropods and vertebrates.

\subsection{Developmental expression of AmphiSmad1/5/8 and AmphiSmad4}

The dynamic expression patterns of the AmphiSmad1/5/8 and AmphiSmad4 were investigated by whole-mount in situ hybridization and real-time PCR. AmphiSmad1/5/8 was detected in all early stage embryos. The transcripts were first detected during the cleavage stage, suggesting that they were maternally supplied (Figure 2A and B). Thereafter, in the blastula stage, the expression decreased and became weakly detectable (Figure 2C). Then strong AmphiSmad1/5/8 transcripts were observed ubiquitously distributed throughout the early, mid and late gastrula stages, with a peak at the late gastrula stage (Figure $2 \mathrm{D}$ and $\mathrm{E}$ ). In the neurula stage, strong signals were detected in differentiating mesoderm and endoderm, especially in the developing myotomes and the wall of alimentary canal (Figure 2G, K and $\mathrm{O})$. In the late-neurula stage, the expression was downregulated in formed myotomes (Figure 2K). At 24 and $36 \mathrm{~h}$ knife-shaped larval stages, transcripts continued to be down-regulated in myotomes (Figure $2 \mathrm{~L}$ and $\mathrm{M}$ ). For the $48 \mathrm{~h}$ larva, the expression was not observed in the anterior part of the body and was restricted to the posterior (Figure $2 \mathrm{~N}$ ).

Similarly to AmphiSmad1/5/8, AmphiSmad4 was also provided maternally, and its transcripts were present before the onset of zygotic transcription (Figure 3A-C). In contrast to AmphiSmad1/5/8, AmphiSmad4 expression level diminished from the blastula stages and was hardly detectable in the gastrula stage (Figure 3D and E). However, the AmphiSmad4 expression increased in the early neural stage (Figure $3 \mathrm{~F}$ and $\mathrm{G}$ ), and was detected in developing presumptive notochord, presomitic mesoderm and the differentiating alimentary canal. In the mid-neural stage, there were continuing transcriptions in alimentary canal, while the expression disappeared in the formed myotomes (Figure $3 \mathrm{H}-\mathrm{J})$. In the late neurula stage, transcripts were limited to the wall of alimentary canal (Figure $3 \mathrm{~K}$ and L). At $72 \mathrm{~h}$ larval stage, the expression was down-regulated in the anterior part of the body (Figure $3 \mathrm{~N}$ ). 


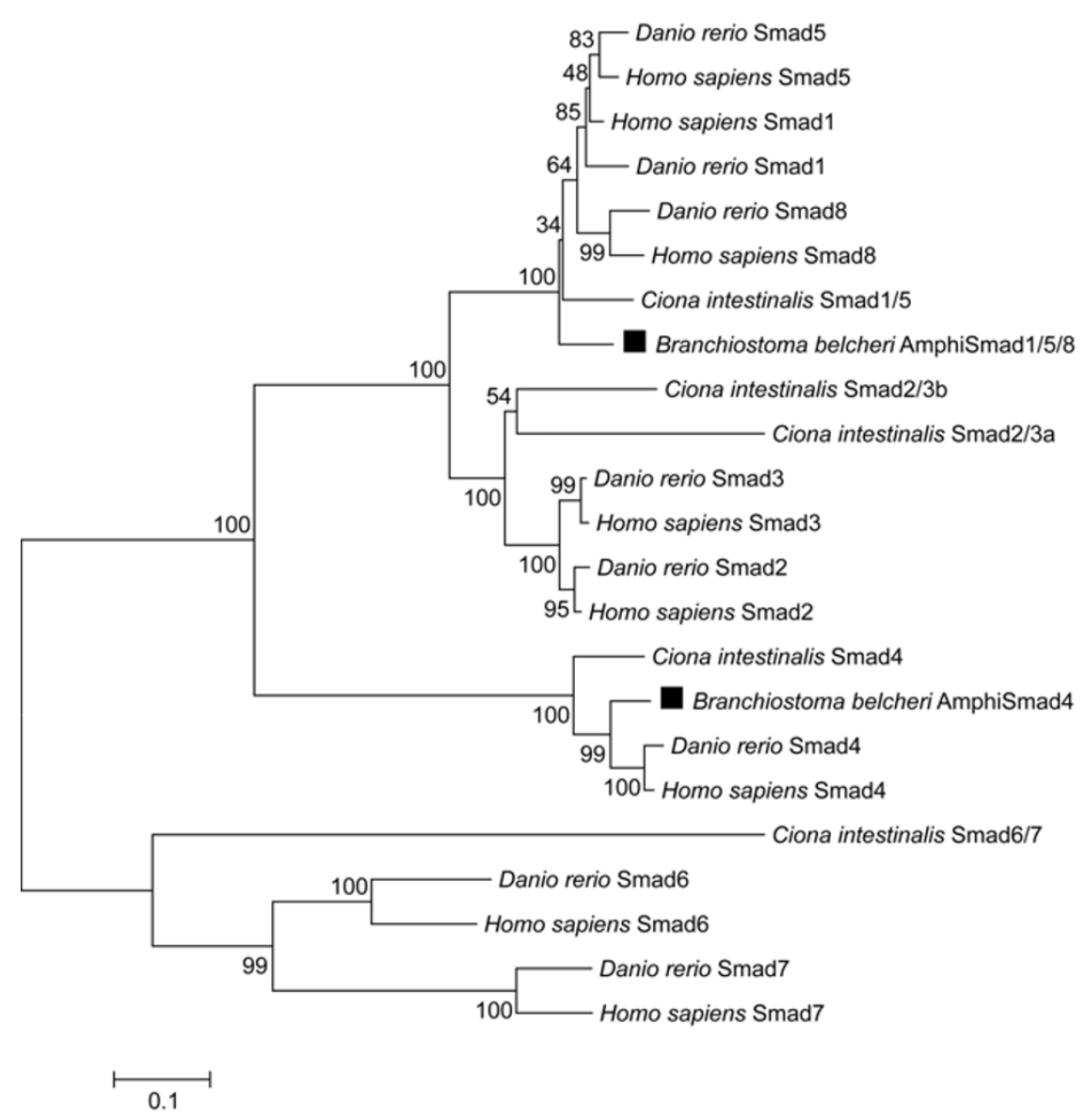

Figure 1 Phylogenetic analysis of AmphiSmad1/5/8 and AmphiSmad4. Sequences were selected from Ciona intestinalis, Danio rerio and Homo sapiens. The phylogenetic tree was constructed by the neighbor-joining method with Mega3.1 based on full-length proteins. Bootstrap majority consensus values on 1000 replicates were indicated at each branch point in percent. Phylogenetic analysis placed AmphiSmad1/5/8 in the Smad1, 5 and 8 subgroup of R-Smad subfamily, and AmphiSmad4 in the Co-Smad subfamily. GenBank accession numbers of the analyzed sequences are as follows: Homo sapiens Smad1 (EAX05040), Homo sapiens Smad2 (EAW62917), Homo sapiens Smad3 (EAW77790), Homo sapiens Smad4 (EAW62987), Homo sapiens Smad5 (NP_001001420), Homo sapiens Smad6 (NP_005576), Homo sapiens Smad7 (NP_005895), Homo sapiens Smad8 (AAI04763), Danio rerio Smad1 (CAX12658), Danio rerio Smad2 (AAI65346), Danio rerio Smad3 (NP_571646), Danio rerio Smad4 (ACA58502), Danio rerio Smad5 (Q9W7E7), Danio rerio Smad6 (CAK10944), Danio rerio Smad7 (NP_778257), Danio rerio Smad8 (AAI65345), Ciona intestinalis Smad1/5 (BAE06690), Ciona intestinalis

Smad2/3a (BAE06691), Ciona intestinalis Smad2/3b (BAE06692), Ciona intestinalis Smad4 (BAE06693), Ciona intestinalis Smad6/7 (BAE06694).

In parallel, a similar pattern of temporal expression was observed by real-time PCR. AmphiSmad1/5/8 expression was detected in all early developmental stages (Figure 4A), and was most abundant at 5.5 (gastrula stage) and $8 \mathrm{~h}$ (early neurula stage), and then the expression was down-regulated at 11-24 h embryos. Compatible with the results of in situ hybridization, AmphiSmad4 was nearly undetectable at 5.5 (gastrula stage) and highly up-regulated at $8 \mathrm{~h}$ (early neurula stage), and then the expression level decreased gradually from 11 to $24 \mathrm{~h}$ embryos. These observations suggested that AmphiSmad1/5/8 and AmphiSmad4 may play an important role in the early development of amphioxus.

\subsection{Tissue distribution of AmphiSmad1/5/8 and Am- phiSmad4}

To investigate the expression pattern of AmphiSmad1/5/8 and AmphiSmad4 among various tissues of the normal adult amphioxus, real-time PCR analysis was performed with gene specific primers. Our results indicated the extensive distribution of AmphiSmadl/5/8 and AmphiSmad4 in all tissues examined, including the gill, skin, muscle, notochord, spermary, ovary, and intestine (Figure 4B). However, the expression levels of the two genes significantly varied among different tissues. The expression of AmphiSmad1/5/8 was observed in all tissues examined, and was especially abundant in the notochord and gonad, but relatively weak in the skin and intestine. For AmphiSmad4, high expression levels were observed in all tissues investigated, particularly in the spermary, notochord and intestine.

\section{Discussion}

In the present study, we have cloned the full-length cDNAs of AmphiSmad1/5/8 and AmphiSmad4 from Chinese am- 


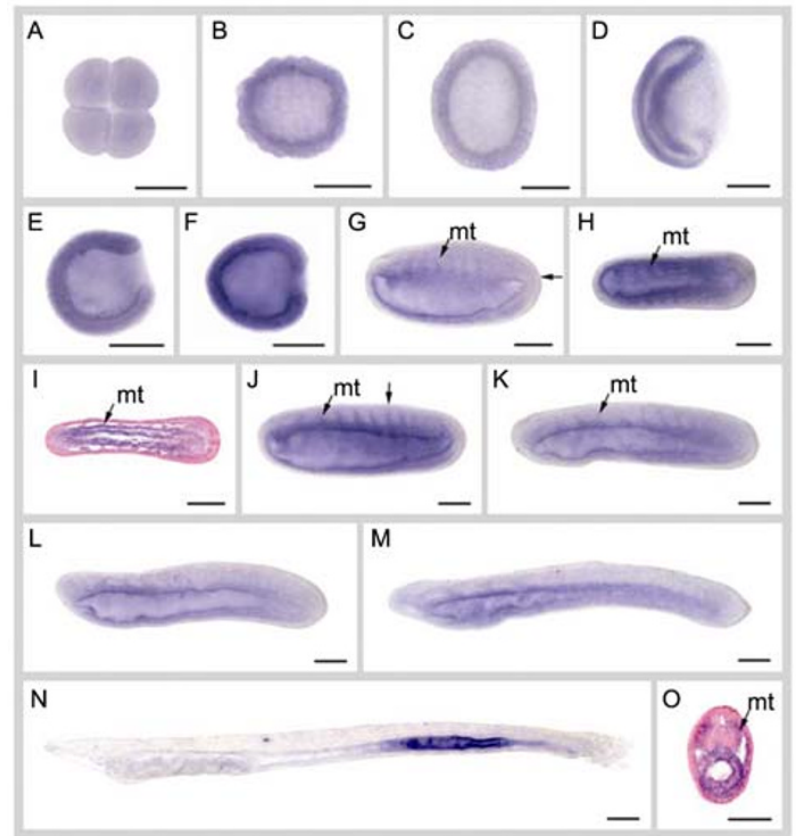

Figure 2 Developmental expression of AmphiSmad1/5/8 was detected by whole-mount in situ hybridization. A and B, Cleavage stages. C, $4 \mathrm{~h}$ blastula. D-F, Early (D), mid (E) and late (F) gastrula. The gene expression was first detected in differentiating mesoderm and endoderm. From $\mathrm{G}$ to N, all the embryos were oriented with anterior to the left and dorsal to the top except for $\mathrm{H}$. $\mathrm{G}-\mathrm{K}$ and $\mathrm{O}$ show developing neurulae, the gene expression was presented in developing myotomes and the wall of alimentary canal. $\mathrm{H}$, The dorsal view of G. I, The horizontal section through arrowhead indicated in G. O, Transverse section through arrowhead indicated in J. K, Late-neurula stage, expression was down-regulated in formed myotomes. $\mathrm{L}$ and $\mathrm{M}$, At 24 and $36 \mathrm{~h}$ larval stages with a knife shape, transcripts continue down-regulated in myotomes. $\mathrm{N}$, The expression was absent in the anterior part of body in $48 \mathrm{~h}$ larva. $\mathrm{mt}$, myotome. Scale bar $=50 \mu \mathrm{m}$.

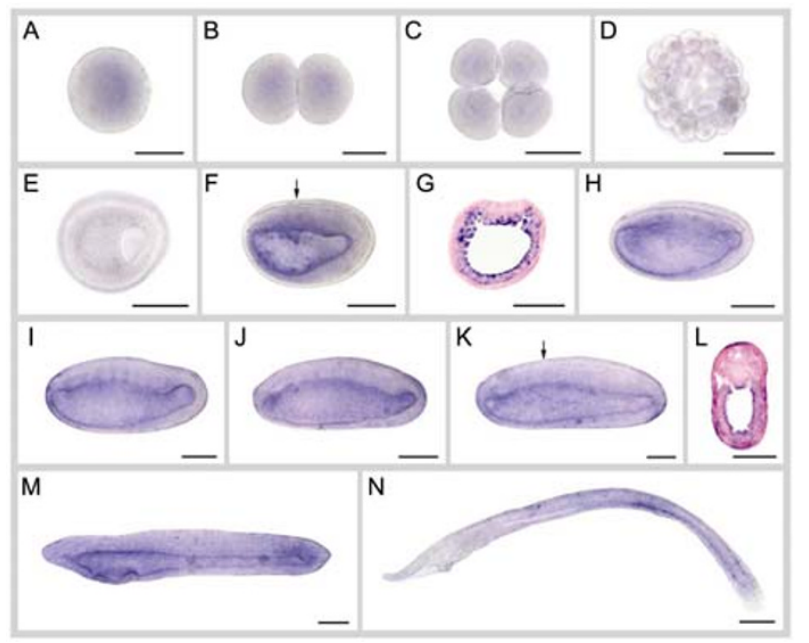

Figure 3 Developmental expression of AmphiSmad4 was detected by whole-mount in situ hybridization. A-L, One-cell (A), two-cell (B), four-cell (C), blastula (D), gastrula (E) and neural stages (F-L). F, H-K, M and $\mathrm{N}$, These embryos were oriented with anterior to the left and dorsal to the top. G, Transverse section through arrowhead indicated in F, where AmphiSmad4 expression was detected in developing presumptive notochord, presomitic mesoderm and differentiating alimentary canal. L, Transverse section through arrowhead indicated in K, where the expression was detected in the wall of the alimentary canal. M, AmphiSmad4 expression continues in the wall of gut of knife-shaped larva; N, AmphiSmad4 expression in the $72 \mathrm{~h}$ larva. Scale bar $=50 \mu \mathrm{m}$.
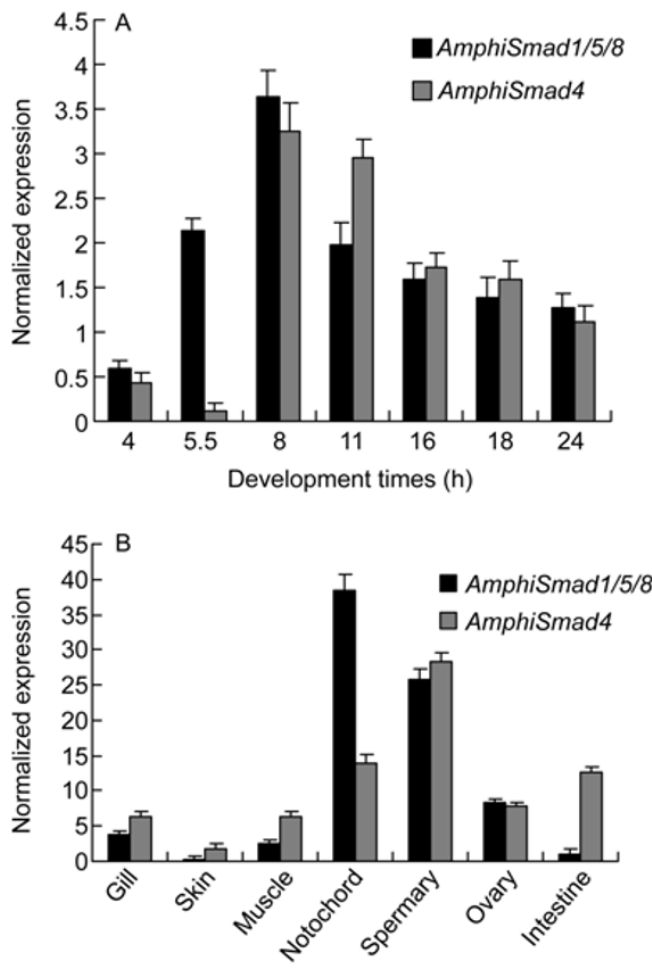

Figure 4 Temporal and spatial expression patterns of AmphiSmad1/5/8 and AmphiSmad4. Quantitative real-time PCR was performed to analyze the expression patterns of AmphiSmad1/5/8 and AmphiSmad4 during development stages (A) and in different tissues of normal adult amphioxus (B). Reaction of each sample was performed in triplicate. The endogenous control for quantification was cytoplasmic $\beta$-actin. Each bar represents the mean of three replicates. Error bars represent standard deviation.

phioxus. To investigate the potential role of the Smad proteins during embryonic development and in the adult amphioxus, we examined the spatial and temporal expression patterns of AmphiSmad1/5/8 and AmphiSmad4 by in situ hybridization and real-time PCR. We focused on AmphiSmad1/5/8 and AmphiSmad4, because they are the archetypal signal transduction molecules of the BMP signaling pathway in invertebrates.

There is increasing evidence that different kinds of Smad proteins play different roles during embryonic development, but the same family of Smad proteins may have conserved functions among different species. As to R-Smad, the two subgroups of Smad function differently. The level of Smad activation is critical in shaping the dorsal-ventral axis. Overexpression of Smadl or Smad5 causes ventralized phenotypes in Xenopus embryos [14-16], similar to the effects of BMP4. By contrast, Smad2 overexpression leads to dorsalization [14,17], similar to the effects of TGF- $\beta$ or activin. The same ventralized/dorsalized embryos by Smad1 and Smad2 were observed in zebrafish [18]. In the current study, AmphiSmad1/5/8 showed a similar expression pattern as its homologs in vertebrates (Smad1, Smad5 and Smad8). The expression of AmphiSmad1/5/8 mRNA was conspicuous in the gastrula and neurula stages. After the neurula stage, the expression was down-regulated with a 
ventral expression pattern. As potential signal transducing molecules, Smad proteins are expected to be co-expressed with the BMP signaling molecules. Amphioxus BMP2/4 and $B M P 5-8$ are co-expressed throughout the vegetal plate, and become down-regulated in the dorsal axial mesoderm. Similarly, in amphioxus, the BMP modulators BMP and activin membrane-bound inhibitor (BAMBI) and Tolloidlike are expressed ventrally [19,20]. Expression of AmphiBMP $2 / 4$ was also detected in the inner layer, especially in the primitive gut and the somitocoelomic system [21]. The expression pattern is consistent with a role for AmphiSmad1/5/8 in transduction of BMP signal and specification of the dorsal-ventral axis of amphioxus.

Smad4 is believed to be an essential factor that mediates all members of TGF- $\beta$ superfamily. As the only Co-Smad identified so far in most species, Smad4 was shown to be able to function as a common coordinator of various R-Smad, and it was ubiquitously expressed during development [22-25]. However, AmphiSmad4 showed a different expression pattern in amphioxus. It was highly expressed in neurula but not in gastrula stage embryos. After the neurula stage, the expression was down-regulated and had a ventral pattern. These results probably indicate that there is another Smad4 that functions as Co-Smad in amphioxus, which may result from the duplication specific to this cephalochordate. Actually, two Smad4s have been identified in Xenopus (XSmad $4 \alpha$ and XSmad4 3 ). Both XSmad4s are able to function as $\mathrm{Co}$-Smad and show distinct developmental expression patterns in the early embryos. Moreover, XSmad4 $\beta$ was proved to be able to induce ventralization, but XSmad $4 \alpha$ unable [26,27]. In addition, four types of Smad4 have been isolated from the common carp, and the different expression patterns of these four types of cSmad4 in different tissues of carp show that each cSmad4 has its own function [28]. However, no further research has been pursued for the Co-Smad proteins, so whether two or more Co-Smad exist in other species remains an intriguing question up to now. More studies are necessary to evaluate the functions of the different types of Co-Smad.

Smad proteins may have important roles in embryogenesis but roles in later development processes and in the adult have not been defined. In normal adult amphioxus, real-time PCR results indicated the extensive distribution of AmphiSmad1/5/8 and AmphiSmad4 in all adult tissues examined. AmphiSmad4 was abundantly expressed in all tissues, particularly in the spermary, notochord and intestine. By contrast, the expression of AmphiSmad1/5/8 varied greatly among different tissues, and was especially abundant in the notochord and gonad with a relatively low level in the skin and intestine. We noted that AmphiSmad1/5/8 and AmphiSmad4 were more highly expressed in most adult tissues compared with embryos. The different spatial expression patterns of AmphiSmad1/5/8 and AmphiSmad4 in the adult amphioxus may mean that these two genes also play important roles in the morphogenesis of a variety of tissues, espe- cially the notochord and the gonad. The expression patterns agree well with the data showing widespread expression of Smad genes in different adult tissues of the vertebrate [24,29]. In comparison, vertebrate Smad genes are expressed in several vertebrate-specific structures, including kidney, heart, neural crest, and limb buds [30-33]. Thus the evolutionary and developmental biology study of Smad gene family of amphioxus will help to elucidate the homology of the body plan between amphioxus and vertebrates, and it will also shed light on the origin and evolution of new structures arising during vertebrate evolution.

From the above data we conclude that AmphiSmad1 and AmphiSmad4 have some conserved functions of Smad family proteins but with a relatively simple function contrasting to their homologues in vertebrates. On the other hand, the Smad signal pathway is conserved between invertebrates and vertebrates, and the composition of the signal pathway and function of the related genes become complicated with the evolution. The data presented herein significantly broaden our knowledge of Smad factors in amphioxus and will facilitate studies on TGF- $\beta$ regulated genes in amphioxus as well as other species.

This work was supported by the National Basic Research Program of China (Grant No. 2007CB815800), the National High Technology Research and Development Program of China (Grant No. 2006330004104456) and the National Natural Science Foundation of China (Grant Nos. 30300264, 30270693 and 30570967).

1 Massagué J, Blain S W, Lo R S. TGF- $\beta$ signaling in growth control, cancer, and heritable disorders. Cell, 2000, 103: 295-309

2 Massagué J, Seoane J, Wotton D. Smad transcription factors. Genes Dev, 2005, 19: 2783-2810

3 Raftery L A, Twombly V, Wharton K, et al. Genetic screens to identify elements of the decapentaplegic signaling pathway in Drosophila. Genetics, 1995, 139: 241-254

4 Sekelsky J J, Newfeld S J, Raftery L A, et al. Genetic characterization and cloning of mothers against dpp, a gene required for decapentaplegic function in Drosophila melanogaster. Genetics, 1995, 139: 1347-1358

5 Shi Y, Massagué J. Mechanisms of TGF- $\beta$ signaling from cell membrane to the nucleus. Cell, 2003, 113: 685-700

6 Inman G J, Nicolas F J, Hill C S. Nucleocytoplasmic shuttling of Smads 2, 3 and 4 permits sensing of TGF- $\beta$ receptor activity. Mol Cell, 2002, 10: 283-294

7 Xu L, Massagué J. Nucleocytoplasmic shuttling of signal transducers. Nat Rev Mol Cell Biol, 2004, 5: 209-219

8 Miyazono K, Ten D P, Heldin C H. TGF-beta signaling by Smad proteins. Adv Immunol, 2000, 75: 115-157

9 Weinstein M, Yang X, Deng C. Function of mammalian Smad genes as revealed by targeted gene disruption in mice. Cytokine Growth Factor Rev, 2000, 11: 49-58

10 Arnold S J, Maretto S, Islam A, et al. Dose-dependent Smad1, Smad5 and Smad8 signaling in the early mouse embryo. Dev Biol, 2006, 296: 104-118

11 Lau M T, Ge W. Cloning of Smad2, Smad3, Smad4, and Smad7 from the goldfish pituitary and evidence for their involvement in activin regulation of goldfish FSH $\beta$ promoter activity. Gen Comp Endocrinol, 2005, 141: 22-38

12 Holland L Z, Laudet V, Schubert M. The chordate amphioxus: An emerging model organism for developmental biology. Cell Mol Life 
Sci, 2004, 61: 2290-308

13 Holland P W. Whole mount in situ hybridization to amphioxus embryos. Methods Mol Bio, 1999, 97: 641-644

14 Graff J M, Bansal A, Melton D A. Xenopus Mad proteins transducer distinct subsets of signals for the TGF- $\beta$ superfamily. Cell, 1996, 85: 479-487

15 Thomsen G H. Xenopus mothers against decapentaplegic is an embryonic ventralizing agent that acts downstream of the BMP-2/4 receptor. Development, 1996, 122: 2359-2366

16 Suzuki A, Chang C B, Yingling J M, et al. Hemmati-Brivanlou, Smad5 induces ventral fates in Xenopus embryo. Dev Biol, 1997, 184: 402-405

17 Baker J C, Harland R M. A novel mesoderm inducer, Madr2, functions in the activin signal transduction pathway. Genes Dev, 1996, 10: 1880-1889

18 Muller F, Blader P, Rastegar S, et al. Characterization of zebrafish smad1, smad2 and smad5: The amino-terminus of Smad1 and Smad5 for specific function in the embryo. Mech Dev, 1999, 88: 73-88

19 Panopoulou G, Clark M D, Holland L Z, et al. AmphiBMP2/4, an amphioxus bone morphogenetic protein closely related to Drosophila decapentaplegic and veterbrate BMP2 and BMP4: Insights into evolution of dorsoventral axis specification. Dev Dyn, 1998, 213: 130-139

20 Yu J K, Satou Y, Holland N D, et al. Axial patterning in cephalochordates and the evolution of the organizer. Nature, 2007, 445: 613-617

21 Yasui K, Saiga H, Wang Y, et al. Early expressed genes showing a dichotomous developing pattern in the lancelet embryo. Dev Growth Differ, 2001, 43: 185-194

22 Yang X, Li C, Xu X, et al. The tumor suppressor Smad4/DPC4 is essential for epiblast proliferation and mesoderm induction in mice. Proc Natl Acad Sci USA, 1998, 95: 3667-3672
23 Dick A, Mayr T, Bauer H, et al. Cloning and characterization of zebrafish smad2, smad3 and smad4. Gene, 2000, 246: 69-80

24 Flanders K C, Kim E S, Roberts A B. Immunohistochemical expression of Smads 1-6 in the 15 day gestatin mouse embryo: Signaling by BMPs and TGF- $\beta$ s. Dev Dyn, 2001, 200: 141-154

25 Luukko K, Ylikorkala A, Makela T P. Developmentally regulated expression of Smad3, Smad4, Smad6, and Smad7 involved in TGF-beta signaling. Mech Dev, 2001, 101: 209-212

26 Howell M, Itoh F, Pierreus C E, et al. Xenpous Smad4 $\beta$ is the Co-Smad component of developmentally regulated transcription factor complexes responsible for induction of early mesodermal genes. Dev Biol, 1999, 214: 354-369

27 Masuyama N, Hanafusa H, Kusakabe M, et al. Identification of two Smad4 proteins in Xenopus. J Biol Chem, 1999, 274: 12163-12170

28 Wang Z Y, Futami K, Nishihara A, et al. Four types of Smad4 found in the common carp, Cyprinus carpio. J Exp Zoolog B Mol Dev Evol, 2005, 304: 250-258

29 Huang S X, Flanders K C, Roberts A B. Characterization of the mouse Smad1 gene and its expression pattern in adult mouse tissues. Gene, 2000, 258: 43-53

30 Howell M, Mohun T J, Hill C S. Xenopus Smad3 is specifically expressed in the chordoneural henge, notochord and in the endocardium of the developing heart. Mech Dev, 2001, 104: 147-150

31 Oxbrugh L, Robertson E J. Dynamic regulation of Smad expression during mesenchyme to epithelium transition in the metanephric kidney. Mec Dyn, 2002, 12: 207-211

32 Kaivo-oja N, Jeffery L A, Ritvos O, et al. Smad signalling in the ovary. Reprod Biol Endocrinol, 2006, 12: 14-21

33 Vargesson N, Laufer E. Negative Smad expression and regulation in the developing chick limb. PLoS ONE, 2009, 4: 1-8

Open Access This article is distributed under the terms of the Creative Commons Attribution License which permits any use, distribution, and reproduction in any medium, provided the original author(s) and source are credited. 